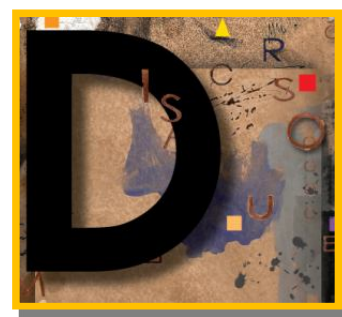

\title{
O BLOGUE CORPORATIVO COMO REPRESENTAÇÃO EMPRESARIAL
}

DISCURSOS CONTEMPORÂNEOS

EM

ESTUDO

ISSN 2237-7247

\author{
Gorete Marques (ESTG-IP Leiria, Portugal) ${ }^{1}$
}

Com a mudança do paradigma comunicacional, despoletada sobretudo pelo impacto tecnológico, proliferaram no universo empresarial ferramentas de comunicação multimodais ligadas à Internet, nomeadamente sítios Web e blogues corporativos. Cabe, neste artigo, o objectivo de analisar as representações multimodais presentes no blogue de um grupo empresarial português. Procura-se, com efeito, a análise das escolhas verbais e visuais, de forma a compreender de que forma o grupo empresarial se representa. Para cumprir este objectivo, seguem-se os princípios da Linguística Sistémico-Funcional (HALLIDAY, 1994, 2004) e da Semiótica Social (KRESS; van LEEUWEN, 1996, 2006) aplicados ao Discurso Empresarial. Os instrumentos analíticos centramse no sistema da transitividade de Halliday e nas estruturas de representação visual da Gramática Visual. Os principais resultados desta análise revelam que, apesar de não cumprir o objectivo de interactividade inerente a este género textual, o blogue representa o grupo empresarial agrupando diferentes recursos e géneros. Conclui-se que o blogue tem uma missão interna e externa, sendo o grupo representado com base em dois universos: o da acção e o da caracterização. O grupo é uma entidade animada e humana que reflecte e age sobre a qualidade e o meio ambiente, mas é igualmente representado pelos seus atributos.

Palavras-Chave: Representações. Transitividade. Estruturas de representação visual. Multimodalidade.

New multimodal tools connected to Internet, such as websites and corporate blogs, have multiplied in the business universe, due to changes in the communication paradigm. The aim of this article is to analyze multimodal representations in the blog of a Portuguese company group. We intend to analyze verbal and visual choices in order to understand how this company group is represented. To accomplish this objective, we follow Systemic Functional Linguistics (HALLIDAY, 1994, 2004) and Social Semiotics principles (KRESS; van LEEUWEN, 1996, 2006) applied to business discourse. The analytical tools are focused on Halliday's transitivity system and on the structures of visual representation of Visual Grammar. The main results of this analysis show that, although the objective of interactivity inherent to this textual genre is not achieved, this blog represents the company group in bringing together different resources and genres. We conclude that it has an internal and external mission, representing, on one hand, the company group as an entity with animated and human characteristics roughly linked to the quality and the environment, and, on the other, through its attributes.

Keywords: Representations. Transitivity. Representation structures. Multimodality.

\footnotetext{
${ }^{1}$ Doutoranda em Linguística Aplicada pela Faculdade de Letras da Universidade de Lisboa; investigadora do grupo Discurso e Literacia no Instituto de Linguística Teórica e Computacional; Bolseira da Fundação para a Ciência e Tecnologia; docente na Escola Superior de Tecnologia e Gestão do Instituto Politécnico de Leiria. E-mail: gorete.marques@ipleiria.pt.
} 


\section{Introdução}

Numa era em que o impacto tecnológico veio alterar concepções no trabalho e na comunicação entre as pessoas, novos recursos e novas formas de comunicar surgiram, dando lugar relevante à imagem. Nesse novo paradigma comunicacional, o visual tem, pois, um papel central na vida contemporânea ocidental e se coaduna com o aumento das interacções com experiências visuais construídas (ROSE, 2007, p. 4). Com efeito, o texto multimodal tem vindo a proliferar como consequência do frequente recurso às numerosas possibilidades de combinações de recursos semióticos promovido pelas novas tecnologias. Nesse sentido, o universo empresarial viu-se confrontado com inúmeras mudanças tecnológicas às quais se teve de adaptar rapidamente. Surgiram, num curto espaço de tempo, sítios web, newsletters, blogues, entre outras ferramentas, com o objectivo de melhorar as comunicações interna e externa entre diferentes participantes. $\mathrm{Na}$ realidade, essas ferramentas trouxeram novas informações sobre as representações das empresas, ou seja, sobre a forma como estas representam a si mesmas e a seus bens/serviços, ou como representam seus clientes.

Nesse contexto, urge acompanhar as tendências do discurso empresarial e proceder à sua análise, com base num enquadramento teórico e em instrumentos analíticos adequados. Desta feita, pretende-se, neste artigo, analisar as representações multimodais presentes no blogue de um grupo empresarial português localizado numa das regiões mais industrializadas de Portugal (Leiria - Centro de Portugal). Visa-se, mais concretamente, analisar as escolhas verbais e visuais, por forma a responder à seguinte questão: o que revelam as escolhas semióticas sobre a empresa? Para tal, seguir-se-ão os princípios da Linguística Sistémico-Funcional (HALLIDAY, 1994, 2004) e da Semiótica Social (KRESS; van LEEUWEN, 1996, 2006) aplicados ao discurso empresarial.

Ao longo deste artigo, descrever-se-á, num primeiro momento, o enquadramento teórico bem como os instrumentos de análise que norteiam este estudo das representações. Seguir-se-á uma breve descrição do género textual blogue, com foco no blogue corporativo. Na terceira parte, proceder-se-á à descrição do corpus em questão, seguindo-se a sua análise semiótica. O capítulo que antecede as considerações finais do estudo explana, de forma geral, os resultados gerais da análise realizada.

\section{Enquadramento Teórico: a Linguística Sistémico-Funcional e a Semiótica Social}

A Linguística Sistémico-Funcional, desenvolvida a partir dos anos 60 por M. A. K. Halliday, com influências nomeadamente de Malinowsky, J. R. Firth, Hjelmslev e da Escola de 
Praga, preocupa-se em perceber de que forma a linguagem é estruturada no seu uso pelas escolhas léxico-gramaticais dos falantes, as quais veiculam significados, considerando que a linguagem serve para construir experiências, para negociar relações e para organizar mensagens com sucesso. A realização simultânea desses três tipos de significados remete, respectivamente, para as três metafunções propostas por Halliday: metafunção ideacional (representações), metafunção interpessoal (relações) e metafunção textual (organização da mensagem), que permitem a compreensão da mensagem como um todo. A realização do significado não se cinge, no entanto, à linguagem verbal, uma vez que esta é apenas um dos sistemas semióticos que, com outros, realiza significados e se relaciona. Este foco sócio-semiótico da linguagem foi uma inspiração para a Semiótica Social que defende que um mesmo significado pode ser comunicado com recursos de representação distintos, inscritos em diferentes sistemas semióticos. Cabe, então, o desenvolvimento de estudos sobre a multimodalidade, definida por Kress e van Leeuwen (2001, p. 20) como: "the use of several semiotic modes in the design of a semiotic product or event, together with the particular way in which these modes are combined".

Nesse enquadramento, Kress e van Leeuwen desenvolvem trabalhos sobre a análise da semiótica visual, publicando a sua Gramática do Design Visual (1996, 2006). Estes autores baseiam-se nas metafunções de Halliday, adaptando-as ao mundo do visual:

we believe that visual design, like language, indeed like all semiotic modes, fulfils two major functions. To use Halliday's terms, every semiotic fulfils both an 'ideational' function, a function of representing 'the world around and inside us' and an interpersonal' function, a function of enacting social interactions as social relations. (KRESS; VAN LEEUWEN, 2006, p. 15)

A partir dessa adaptação, a imagem é entendida como representação do mundo (significado representacional) e como interacção com os participantes (significado interaccional) e com os seus próprios elementos (significado composicional). Tal não significa, porém, que se pretenda uma transposição directa das estruturas linguísticas e visuais, uma vez que nem tudo o que se realiza pela linguagem verbal se realiza pela visual ou vice-versa. Salienta-se, por fim, que esta proposta é inovadora pelo entendimento das estruturas visuais como produtoras de imagens da realidade ligadas às instituições sociais nas quais são produzidas, circulam e são lidas.

Considerando o objecto concreto deste estudo, i.e., as representações semióticas do grupo empresarial, a análise foca-se apenas na metafunção ideacional, na função experiencial e no significado representacional, bem como nos seus respectivos instrumentos analíticos.

A representação da experiência ocorre na metafunção ideacional, o que significa que o falante usa a linguagem verbal para representar a sua experiência, para descrever eventos e 
estados, bem como as entidades envolvidas. A linguagem permite-lhe, pois, criar uma representação mental da realidade para fazer sentido do que acontece à sua volta e na sua mente: "Language enables human beings to build a mental picture of reality, to make sense of what goes on around and inside them" (HALLIDAY, 1994, p. 106). A representação da realidade pode ser analisada por meio do significado experiencial, o qual é expresso na oração pelo sistema da transitividade que constrói o mundo da experiência no conjunto de tipos de processos (HALLIDAY; MATTHIESSEN, 2004, p. 170). A transitividade, por sua vez, permite que se perceba de que forma as categorias semânticas se inter-relacionam, pela análise de: (i) processos (realizados pelo grupo verbal), (ii) participantes no processo (realizados por grupos nominais e sintagmas preposicionais) e (iii) circunstâncias associadas ao processo (realizadas por grupos, sobretudo por adverbiais e preposicionais), para que se entenda que diferentes escolhas no nível da transitividade permitem diferentes representações do mesmo evento. A diferenciação reside na escolha do tipo de processo, o elemento fulcral da oração que especifica, por sua vez, o participante. De referir que, apesar de o participante ser normalmente realizado pelo grupo nominal, pode não ser representado explicitamente.

No sistema de transitividade, Halliday divide as categorias semânticas em três processos principais: (i) processos mentais, que representam a experiência do mundo interior, da consciência, do sentir e do saber; (ii) processos materiais, que representam o fazer, o mundo exterior e (iii) os processos relacionais, que relacionam fragmentos de experiência, classificam e identificam. Estes últimos dividem-se em processos relacionais identificativos e atributivos. Nos limites destes processos principais, outros processos partilham algumas das suas características: (iv) na fronteira entre os processos materiais e mentais, existem os processos comportamentais, que representam a manifestação exterior de processos de consciência e de estados fisiológicos; (v) na fronteira dos processos mentais e relacionais, encontram-se os processos verbais, que representam, na linguagem; relações simbólicas construídas na consciência humana, com processos como dizer; (vi) na fronteira entre os processos relacionais e materiais, situam-se os processos existenciais em que os fenómenos são reconhecidos por serem, existirem ou acontecerem.

Cada processo possui um esquema de construção de um domínio particular de experiência, ao qual se associam participantes em determinadas circunstâncias. Essas categorias semânticas vêm, assim, representar, linguisticamente, o que se passa no mundo.

No significado representacional, Kress e van Leeuwen $(1996,2006)$ apresentam duas estruturas de representação em textos multimodais: a representação narrativa e a representação conceptual, que, salientam, não são estanques. A primeira representa acção ou transformação, 
enquanto a segunda representa os participantes de forma estática, ou seja, em termos da sua estrutura, classe ou significado.

$\mathrm{Na}$ representação narrativa, um elemento fundamental é o vector, que indica uma direcção ou diferentes processos. Neste mundo, diferentes participantes podem existir numa acção, como se descreve brevemente de seguida: (i) um actor que pode ser o único participante (processo não-transaccional) e partir do vector ou ser o vector; (ii) um actor e um vector que se dirige para uma meta (processo transaccional unidireccional), ou uma relação de bidireccionalidade (processo transaccional bidireccional), em que se encontram interactores; um vector e uma meta numa representação na qual decorre uma acção sem que se saiba quem ou o que a desencadeou, sendo o actor anónimo ou estando apagado. O vector existe igualmente nos processos reaccionais, nos quais é formado pela direcção do olhar do reactor possuidor de características humanas. A sua direcção pode ligar-se a um fenómeno (processo transaccional) ou não (processo não transacional). Também os dizentes e experienciadores, quando ligados por balões a conteúdos de fala ou mental, como no caso da banda desenhada, fazem parte deste mundo narrativo. Em representações em que um participante funciona como meta em relação a um determinado participante e como actor em relação a outro participante, verifica-se uma cadeia de processos transaccionais. Por fim, a representação narrativa também pode ser associada ao simbolismo geométrico, que inclui apenas vectores indicadores de direccionalidade, como vectores em forma de hélice ou setas.

A representação conceptual divide-se, de forma geral, em três tipos de processos: classificacionais, analíticos e simbólicos. No primeiro caso, há lugar a uma taxonomia que caracteriza os participantes em termos de características comuns. Esses participantes relacionamse em categorias de subordinação: subordinados que se relacionam com um participante superordenado, em taxonomias fechadas, niveladas ou multiniveladas. Neste último caso de representação, o nível intermédio é ocupado pelos participantes interordenados. No segundo caso, os processos analíticos representam um portador e os seus atributos possessivos, ou seja, uma estrutura de todo-parte. Os processos analíticos subdividem-se em estruturas não estruturadas (nas quais estão presentes apenas os atributos) e estruturadas (temporais e espaciais). Os processos estruturados espaciais subdividem-se em processos exaustivos e inclusivos, mediante o facto de representarem exaustivamente os atributos possessivos do portador ou apenas alguns dos atributos do portador que, com ele, partilham o espaço. Os processos podem também ser topográficos ou topológicos, havendo situações em que ambos coexistem. Kress e van Leeuwen (2006) apresentam, ainda, as estruturas analíticas espáciotemporais para os casos em que há uma combinação entre uma estrutura analítica de espaço e uma linha do tempo (por exemplo num gráfico bidimensional). Por fim, os processos simbólicos 
representam o que um participante significa, ou é, e dividem-se em dois tipos de estruturas simbólicas: processos simbólicos atributivos, associados a um portador, cujo significado ou identidade são estabelecidos, e o atributo simbólico, que representa o significado ou a identidade em si; processos simbólicos sugestivos, com apenas um participante, o portado, que representa o significado e a identidade.

\section{O Blogue Corporativo}

As definições de weblogue, ou mais vulgarmente blogue, referem-no a um sítio da Internet, frequentemente actualizado, dinâmico e interactivo, no qual se colocam mensagens datadas. Stauffer (2002, p. 4) definiu o blogue como um sítio internet, implementado por um software especial, actualizado cronologicamente, com entradas temporais, como se de um diário se tratasse, não obstante os temas de domínio público. A inovação tecnológica levou a que a criação de um blogue fosse acessível a qualquer utilizador da internet. Em consequência, assistiu-se à proliferação de blogues sobre os mais variados assuntos, pelo que a sua natureza, tal como a sua própria definição, encontram-se ainda em processo de construção.

Para um utilizador comum da Internet, o blogue continua a ser associado a um carácter essencialmente pessoal e/ou lúdico, no qual, num estilo informal, partilham-se pensamentos ou informações sobre inúmeros assuntos. Realça-se, no entanto, que a concepção do blogue evoluiu e, no caso particular do blogue no contexto empresarial, constata-se que este não possui as mesmas características do blogue tradicional. Aliás, se este último proliferou exponencialmente, a comunidade empresarial foi mais lenta na sua adopção como ferramenta de comunicação (FLYNN, 2006, p. 6). Com base em Simonis (2008), considera-se que o blogue aqui em análise se enquadra na denominação de blogue corporativo. Mais concretamente, segue-se a seguinte definição:

A corporate blog is a blog published by or with the support of an organization to reach that organization's goals. In external communications the potential benefits include strengthened relationships with important target groups and the positioning of the publishing organization (or individuals within it) as industry experts. Internally blogs are generally referred to as tools for collaboration and knowledge management (WACK ̊, 2004).

A definição acima foca uma nova concepção do blogue, que se afasta do seu conceito "tradicional" no nível dos seus objectivos, participantes e características. É uma ferramenta que deve funcionar de acordo com os objectivos da organização e que pode adquirir uma função 
externa, a que se associa uma estratégia de marketing, ou interna, como plataforma de conhecimento e colaboração. Uma organização que pretenda desenvolver relações com o público externo, nomeadamente com clientes ou com os média, recrutar colaboradores, testar produtos/serviços ou gerir o conhecimento e a cooperação dos colaboradores, internamente pode, se for adequado, optar por criar um blogue.

Por sua natureza diversificada, esse tipo de blogue é caracterizado em diferentes categorias, conforme diferentes autores como Dugan (2004), Shanshan e Q. Zhang (2007) e Wackå (2005). Independentemente da sua forma de categorização, o blogue corporativo pode, de facto, cumprir diferentes missões: (i) ser uma ferramenta de venda de produtos e serviços cujo público-alvo são (potenciais) os próprios clientes; (ii) criar, manter ou fortalecer relações com determinado público-alvo, nomeadamente com clientes; (iii) fortalecer uma marca, um produto ou o perfil de uma organização; (iv) partilhar informações ou conhecimento como repositório perante os colaboradores internos; (v) fornecer ferramentas de pesquisa que promovam a discussão de ideias entre os colaboradores internos ou (vi) fortalecer a cultura organizacional interna por meio dos conteúdos informais.

\section{Descrição do corpus}

O corpus em análise pertence ao grupo Electrofer, de origem familiar, constituído actualmente por cinco empresas na área do fabrico e montagem de estruturas metálicas e tratamento de superfícies. A escolha do referido grupo para a presente pesquisa cumpre o objectivo de associar uma investigação de doutoramento em Linguística Aplicada ao contexto empresarial português. Mais concretamente, fomenta a colaboração entre o universo académico e o universo empresarial da região de Leiria, uma das regiões mais industrializadas do país.

O blogue desse grupo foi criado pela responsável do Departamento de Comunicação e Imagem, a 16 de setembro de 2009, no endereço http://electrofergrupo.blogspot.com. À data de acesso (2 de janeiro de 2010), encontravam-se disponíveis 21 mensagens, das quais 18 (12 em setembro e 6 em outubro) são de 2008, e 3, de janeiro de 2009. Para elas, não constam quaisquer comentários de resposta. Este é um blogue interessante na medida em que, de acordo com a responsável, a informação disponível se destina fundamentalmente ao consumo interno. Considera-se, todavia, que o blogue possui um carácter simultaneamente interno e externo. Por um lado, funciona como um blogue de conhecimento interno, repositório e meio de partilha de informação, onde se integram, a título de exemplo, as guias de transporte das empresas Electrofer II e Supertrat, uma folha de requisição da empresa ETS ou as novas senhas de almoço; 
por outro lado, o blogue funciona como marca que pretende fortalecer o perfil da empresa perante o público externo. Esta acção é visível nomeadamente pelos anúncios de emprego, de um autocolante com a nova morada do grupo, de uma fotografia de um presente para clientes ou de uma publicação de políticas do grupo.

\section{Análise Multimodal do corpus}

Apesar de o blogue em estudo não corresponder ao critério de comunicação frequentemente assumido para este género e de não ter sido actualizado recentemente, entende-se ser um corpus passível de análise por continuar disponível em linha. As suas mensagens dirigem-se, quer para o interior do grupo, quer para o exterior, num conjunto em que o recurso visual é inequivocamente o mais utilizado.

A primeira mensagem é composta por um anúncio de oferta de emprego da Electrofer II. Visualmente, o anúncio reparte-se em diferentes representações, predominando o processo narrativo accional, com ênfase no actor (soldador). De notar que, embora se observe o resultado da acção, as faúlhas, a meta não está directamente presente, definindo-se este processo como não transaccional. Abaixo, numa divisão composicional separada, a representação visual é conceptual. Nesta parte, as fotografias de obras já realizadas (à excepção da última) são apresentadas como atributos inclusivos, acompanhados de um processo analítico cujo portador é o grupo representado pelo logótipo. Não obstante a separação das imagens pelo enquadramento, defende-se que os processos conceptuais da sequência de imagens se encaixam no processo narrativo como processos encaixados. No nível do verbal, o nome da empresa, ligado ao logótipo, aparece como actor do processo material "recrutar", associado às profissões (meta). O material também aparece no processo "oferecemos", cuja desinência remete para a empresa e cuja meta se reparte em condições de emprego ("Remuneração (...); "Integração (...)"; "Formação").

O blogue contém três mensagens dedicadas à política do grupo, mais concretamente à sua política de qualidade de meio ambiente e de segurança, colocadas em linha no mesmo dia. Pelo seu campo (a política do grupo), considera-se que, de forma geral, os participantes, bem como os processos se harmonizam nos três textos. No primeiro texto, a política de qualidade do grupo, bem como a sua gestão são representadas essencialmente por processos mentais cognitivos e relacionais atributivos, conforme os exemplos abaixo: 
1. A Gestão de topo do Grupo Electrofer considera que a qualidade e o respeito pelo meio envolvente são factores de importância decisiva para a competitividade, o desenvolvimento e o sucesso de todas as empresas que dele fazem parte.

2. O Grupo Electrofer tem como princípio manter um comportamento ético e responsável nas relações com clientes, funcionários, fornecedores, concorrentes, órgãos governamentais, comunidade e meio ambiente.

3. Neste enquadramento geral, a Política da Qualidade suporta-se nos seguintes objectivos.

4. A Gestão de topo do Grupo Electrofer bem como a sua Directoria entende que a Qualidade é um aspecto tão importante da sua actividade.

No que diz respeito aos processos mentais considerar e entender, eles se associam, por um lado, a experienciadores como "A Gestão de topo do Grupo Electrofer" e "A Gestão de topo do Grupo Electrofer bem como a sua Directoria", e, por outro, a orações metafenomenais mentais projectadas com processos relacionais, como se observa no exemplo (1). Nos exemplos analisados, a oração mental projecta outra oração (ou combinações de outras orações) como representação do conteúdo da oração mental, dando lugar a orações denominadas "idea clauses". Nessas orações, a qualidade e o respeito pelo meio envolvente são representados como identificadores. "O Grupo Electrofer”, no exemplo (2), e "A Política da Qualidade”, no exemplo (3), aparecem como portadores dos atributos "princípio" de política e os seus "objectivos", respectivamente. Salienta-se, por fim, a existência de uma elipse na posição de sujeito numa oração iniciada por "Compromete-se". A este processo, aliar-se-ia o grupo e a directoria como experienciador, mas, não obstante a elipse, mantém-se a ideia de que a garantia da qualidade sobressai pela escolha do processo.

No segundo texto, referente à política ambiental, o grupo empresarial representa-se directamente: "O GRUPO ELECTROFER", repetindo-se como experienciador, dizente e actor, como se pode verificar nos exemplos.

5. O GRUPO ELECTROFER considera que a qualidade e o respeito pelo meio ambiente são factores de importância decisiva para a sustentabilidade e sucesso da empresa.

6. Divulga interna e externamente os seus compromissos de protecção ambiental de modo a envolver todos os colaboradores, fornecedores, clientes e entidades públicas interessadas. 
7. Estabelece um conjunto de objectivos e metas e procede à sua revisão e actualização no sentido da melhoria contínua do seu desempenho ambiental e da prevenção da poluição.

A sua forte representação associa-se, pois, a processos mentais cognitivos, verbais e materiais, como considerar, divulgar e proceder. A sua diversidade vem cumprir o objectivo de promoção da sua política, pela reflexão sobre a qualidade e o meio ambiente, pelo compromisso consciente na defesa deste e pela definição de objectivos concretos que dá a conhecer. A sua postura é enfatizada, ao longo do texto, por circunstâncias de modo que demonstram a forma como o grupo se compromete, bem como o seu alcance em relação aos colaboradores internos externos.

A política de segurança é o título do terceiro texto, no qual os principais participantes são o Grupo Electrofer e os seus objectivos globais. A representação segue a estrutura dos dois textos anteriores no sentido de que o grupo aparece como experienciador do processo mental cognitivo, e a circunstância de modo enfatiza a sua tomada de posição.

8. O Grupo Electrofer, ao seu mais alto nível, compromete-se a adoptar práticas de prevenção de acidentes e doenças profissionais, bem como a rever e melhorar continuamente o sistema de SST, cumprir com a legislação de SST aplicável à organização e adequação à natureza e à escala dos riscos das actividades desenvolvidas na sua organização.

Os objectivos são especificados por meio de um processo relacional intensivo identificativo: identificado ("Os objectivos globais de segurança”) e identificador (na sua especificação).

O domínio do material no blogue projecta-se claramente no campo da preocupação com o meio ambiente e com a segurança, pela inserção de cartazes em várias mensagens. A título de exemplo, refira-se ao título da mensagem "RECICLAR NA ELECTROFER NÃO CUSTA NADA!", bem como ao título do cartaz sobre reciclagem "Separar o lixo na Electrofer", os quais destacam a circunstância de localização espacial (o grupo e a empresa Electrofer 3) associada à acção ambiental. Também sobre segurança, a inserção de um cartaz "Instrução de Segurança" espraia as medidas a se adoptar em situação de acidente na empresa pelo uso de processos materiais no infinitivo. $\mathrm{O}$ interesse ambiental e social revela-se igualmente em duas mensagens dedicadas à exposição Fotonaturis, realizada em Leiria (Portugal), com o apoio da Electrofer II. 
O título da primeira mensagem, "ELECTROFER APOIA NATURIS”, representa o grupo como actor, associado ao processo "apoia" e à meta "Fotonaturis", o que se repete no início do texto, em que o grupo é representado como actor numa relação de continuidade, uma vez que apoia "mais uma iniciativa". A Fotonaturis (meta) e a iniciativa (meta) são efectivamente uma “exposição de exterior”. No papel de identificado, a exposição associa-se a um processo relacional circunstancial identificativo: "fica ao mesmo nível de" e a uma longa circunstância de localização espacial que lhe confere importância pelo contexto em que se insere (zona nobre da cidade). O texto contém ainda circunstâncias de modo e de localização temporal e processos mentais que remetem para a exposição. Termina com um processo material "Visitem!" que impele à acção dos destinatários. É com essa mesma ideia que se iniciará a segunda mensagem colocada dez dias depois.

O cartaz oferece uma representação dupla, considerando, por um lado, o banner e, por outro, a fotografia. Começando pelo banner, observa-se uma ênfase na meta "Tesouros da Vida Selvagem" do processo "preservar", sem que haja um actor explícito. A representação visual realiza-se conceptualmente, por um processo classificacional. Os participantes, representados pelos logótipos, relacionam-se taxonomicamente entre eles, numa relação de superordenado/subordinados. Os primeiro destacam-se em tamanho em relação aos segundos, que se encontram numa composição simétrica, à mesma distância uns dos outros, com o mesmo tamanho e orientação. No que respeita à fotografia, a representação é narrativa reaccional constituída por vários vectores formados pelo olhar dos reactores, havendo também lugar a processos de acção. Observam-se, todavia, situações de reacção díspares: (i) a representação de reacção não transaccional em que o vector é formado pelo olhar do reactor, que não aponta para outro participante; (ii) a representação de reacção transaccional em que o vector formado pelo olhar liga o reactor e o fenómeno. Repare-se que também se encontra acção transaccional quando um actor caminha em direcção à exposição. Acresce igualmente a importância da circunstância de localização cenário, como pano de fundo, que, tal como no texto verbal, apresenta o local específico da exposição. A segunda mensagem, cujo título é uma ordem de acção - "VISITEM A EXPOSIÇÃO FOTONATURIS" -, repete a fotografia acima analisada, mas enfatiza o apoio da empresa. A mudança de composição do cartaz altera as representações, à excepção da fotografia diurna. Não obstante a composição não ser aqui objecto de estudo, importa observar a configuração Dado-Novo na estrutura topo (Ideal), fundo (Real). O logótipo da empresa surge realmente no topo, enquanto o banner da exposição aparece no fundo. Salienta-se ainda, no aspecto verbal que, enquanto o texto verbal da primeira mensagem não se encontra no cartaz, este cartaz possui informação análoga à parte da outra mensagem. O grupo é actor ligado à meta “iniciativa cultural” e à circunstância da Extensão Temporal "até ao dia 26 de outubro". O texto 
termina com a incitação à visita por parte dos destinatários da mensagem. No conjunto do cartaz, poder-se-á, então, observar a existência de diferentes processos de representação visual. Por um lado, o conceptual e, por outro, a narrativa. A empresa aparece como um portador do evento, numa posição diferente do cartaz anterior, destacando-se na composição do cartaz.

Na mensagem “UM PRESENTE PARA OS NOSSOS CLIENTES!", a representação se divide entre a dos clientes e a do grupo. Os clientes são representados como experienciadores de um processo mental cognitivo e, indirectamente, como beneficiários da meta (caixa de bases de copos). O grupo representa-se visualmente pelas imagens presentes nas bases de copo (oferta para os clientes), numa perspectiva conceptual. A sua acção de oferta, o uso do determinante possessivo em "algumas das nossas obras", bem como a sua referência como fenómeno mostram um grupo atento à manutenção das relações comerciais e ao seu design.

Mensagens como GRUPO ELECTROFER (logótipos do grupo e das empresas); APLICAÇÕES [folha de carta, envelope, cartões]; GUIA DE TRANSPORTE SUPERTRAT; REQUISIÇÃO ETS; FITA COLA E3 E4; CONTENTOR; GUIA DE TRANSPORTE E2; NOVAS SENHAS DE ALMOÇO e AUTOCOLANTE NOVO APARTADO reflectem um blogue que funciona como uma vitrina do grupo. Trata-se, em todas as imagens, de uma representação conceptual, que mostra o grupo ou uma empresa em termos da sua essência. Esta representação realiza-se sempre com a presença de logótipos que estabelece uma relação analítica entre portador e atributos.

O carácter expositivo mantém-se igualmente na inclusão de fotografias da publicação do anúncio de oferta de emprego, anteriormente publicado no blogue, ou na descrição da empresa. A observação é, essencialmente, visual, com carácter interpessoal, dado que se denota a intenção de mostrar a existência de uma publicação por um órgão externo ao grupo. Este carácter repetese na mensagem da fotografia da brochura da Electrofer 3 e do seu interior, visto este nem ser perceptível, ou na publicação do OECP (Operação Emissão Papel Comercial). Na capa deste último, o grupo representa-se pelo seu logótipo e, apesar do enquadramento realizado pelas cores, o logótipo, o título e a imagem fazem parte de um todo. A fotografia representa acção, é narrativa, pelo próprio vector do comboio. Porém, interessa salientar que a ponte, construída pelo grupo, deve ser objecto de análise visual, dado que é o atributo do grupo (portador) que se pretende evidenciar. Realizam-se, deste modo, os dois tipos de representação que se conjugam. 


\section{Resultados gerais}

A primeira evidência geral que se retira do blogue é o facto de se destinar a um público interno e a um público externo, sem qualquer interacção ou comentário de resposta. Apesar de o seu formato ser o de um blogue, lembra indubitavelmente a primeira fase dos sítios Web, que funcionavam como repositórios de informação. Da análise multimodal realizada, às mensagens do blogue sobressaem diferentes representações do grupo, que age, que funciona como actor representado, quer pela sua gerência (verbalmente), quer pelo colaborador (visualmente), quer, ainda, pela própria designação do grupo - "A Electrofer apoia". Visualmente, salienta-se a representação conceptual analítica que representa o grupo e as suas obras realizadas. Verifica-se uma preocupação em mostrar as obras, ou seja, a empresa tem valor pelas obras que já concretizou.

Nos textos relativos à política do grupo, salientam-se três tipos de processos: mentais, materiais, relacionais e, em menor número, verbais. A eles associam-se essencialmente, por um lado, a gerência do grupo e, por outro, a qualidade, o meio envolvente, o meio ambiente, os objectivos e os compromissos desse grupo. A gerência manifesta-se como uma entidade que reflecte sobre a qualidade e a segurança do grupo e o respeito pelo meio ambiente; que divulga os seus compromissos, interna e externamente, e que apresenta os seus objectivos e as suas acções. A preocupação ambiental destaca-se não só no discurso da empresa, como também no visual, pela inclusão de cartazes sobre reciclagem e manuseamento de matérias perigosas. Neste sentido, pode-se entender esta escolha como um apelo à cooperação dos colaboradores e como uma forma de mostrar a sua política para o exterior. As mensagens sobre a exposição Fotonaturis continuam na relação com o meio ambiente. A maior empresa do grupo aparece como actor, agente da realização da exposição na cidade de Leiria, com o mote da preservação do ambiente. Salienta-se, por fim, a representação dos clientes na mensagem que inclui as bases de copos. Os clientes são representados como beneficiários, mas também como experienciadores.

\section{Considerações finais}

A análise realizada com base na Linguística Sistémico-Funcional (LSF) e na Semiótica Social possibilita um estudo bem distante das teorias formalistas da linguagem que concebem a gramática apenas como um conjunto de regras que se preocupam essencialmente com as formas das estruturas gramaticais e das relações lógicas entre elas. Com efeito, viu-se, na análise, que a língua é como uma rede de sistemas ou conjuntos de opções para a realização de significado (HALLIDAY, 1994, p. 15), ou seja, é um sistema semântico de produção de significados que 
residem em padrões sistémicos de escolha (HALLIDAY; MATTHIESSEN, 2004 p. 23). Ora, a produção e a troca de significados estão estreitamente ligadas a um contexto cultural e social no qual são usadas. Em concreto, o grupo não optou por determinadas escolhas semióticas de forma aleatória para se representar. Essas escolhas foram um produto do processo social e cultural. Nesta senda, cabe realçar que as escolhas observadas no blogue, dirigido a um público interno e a outro externo, traduzem como é que o grupo pretende ser visto pelos seus colaboradores internos e pelos seus clientes ou visitantes. Salienta-se que este blogue não tem qualquer interactividade, visto que funciona apenas como uma montra do grupo.

Conclui-se que o grupo se representa como dinâmico, valorizador das obras que já realizou (visíveis no visual), preocupado com a qualidade com o ambiente, realçados nos textos da sua política, nos cartazes, bem como nas iniciativas que apoia. Essa dimensão ambiental é interessante e transmite credibilidade na medida em que se trata de um grupo que se dedica ao fabrico e montagem de estruturas metálicas e ao tratamento de superfícies. A escolha dos processos associados ao participante revelam um grupo com características animadas e até mesmo humanas: o grupo age e pensa. Realça-se também o facto de o blogue funcionar como divulgador da identidade do grupo internamente pela publicitação de material de uso interno. A opção pela sua divulgação tem de se associar ao contexto do grupo. $\mathrm{Na}$ verdade, apenas recentemente as empresas passaram a coabitar no mesmo espaço físico. Há, efectivamente, uma história e uma identidade passadas, independentes, para cada uma das empresas, pelo que o dar a conhecer o grupo é, em suma, um objectivo que perpassa a dimensão do público externo.

\section{Referências}

DUGAN, K. Emerging corporate blog models. Strategic public relations - focused on strategy within integrated marketing communication. Disponível em: <http://prblog.typepad.com/strategic_public_relation/2004/11/emerging_corpor.htmla〉. Acedido em:. 12 Dez 2009.

FLYNN, N. Blog rules: a business guide to managing policy, public relations and legal issues. New York: AMACOM, 2006.

HALLIDAY, M. A. K. An introduction to functional grammar. 2. ed., London: Edward Arnold, 1994.

HALLIDAY, M. A. K.; MATTHIESSEN, C. M. I. M. An introduction to functional grammar. 3. ed. London: Hodder Arnold, 2004.

KRESS, G.; van LEEUWEN, T. Multimodal discourse: the modes and media of contemporary communication. London: Arnold, 2006. Reading images. 2. ed. London: Routledge, 2006.

ROSE, G. Visual methologies: an introduction to the interpretation of visual materials. London: Sage, 2007.

SIMONIS, L. The new rules of business http://www.positioningstrategy.com/ebooks/new_Rules_Of_Business_Blogs.pdf, 2008>. Acedido em: 22 Fev 2010.

STAUFFER, T. Blog on: building online communities with web logs. McGraw-Hill, 2002.

WACKA, F. Corporate blog: a short definition. Your guide to corporate blooging info: archive. Disponível em: <http://www.corporateblogging.info/2004/06/corporate-blog-short-definition.asp>. Acedido em: 20 jan 2010.

. Beginners' guide to corporate blogging. Disponível em: 〈http://www.corporateblogging.info/basics/corporatebloggingprimer.pdf>. Acedido em: 15 nov 2005.

MA, Shanshan; QUIPING, Zhang. A study on content and management style of corporate blogs. SCHULER, Douglas (ed.). Online Communities and Social Computing Second International Conference (OCSC), 2007 HCI International, 2007. 